\title{
PRAKTIESE TEOLOGIE MONDIG?
}

\author{
H J C PIETERSE
}

\section{Inleiding}

Sedert die Praktiese Teologie in 1774 as universiteitsvak in Oostenryk ingestel is, was sy legitimiteit as ' $n$ wáárdige universiteitsvak steeds twyfelagtig. Daar loop 'n dik lyn deur die geskiedenis van die vak wat daarop dui dat die Praktiese Teologie ten diepste maar net die uitsprake van die ander teologiese vakke, hoe ook al, prakties moes makk en toepas. Selfs die pas gepubliseerde Practical Theology van Amerikaanse sy, waaroor hoog opgegee word, is op die keper beskou maar net weer ' $n$ indiensstelling van die Praktiese Teologie om etiese doelstellings te verwesenlik."

'n Belangrike stimulus tot die ontwikkeling van die moderne Praktiese Teologie ná die Tweede Wêreldoorlog was die klem wat die hermeneutiese teologie gelê het op die hede en op die historiese situasie van die eietyd. Die teologiese belang van die ervaring van die gelowiges is al meer ingesien. Uitmuntende teoloë het dit uitgespel, onder meer Gerhard Ebeling, E. Schillebeeckx, H.M. Kuitert en J. Macquarrie. ${ }^{2)}$ Vir die Praktiese Teologie, wat die praktyk van die geloof, of anders gesê, die christelike geloofshandelinge tot objek van studie het, is dié ervaring van uiterste belang. Hierdie saak raak ook 'n fundamenteel-teologiese tema, nl. geloof en ervaring. Fundamenteel-teologiese temas in dié verband is veral geloof en rede, geloof en verstaan, geloof en ervaring, geloof en praxis. ${ }^{3)}$ Die groot vraag is egter welke toegang ons tot hierdie ervaring in die eietydse gemeentelike situasie het.

Teoloë huiwer nie meer om situasie-analises te maak nie. Daar is verskeie weë beproef soos fenomenologiese en strukturele analises. " $D$ it is egter 'n vraag hoe verteenwoordigend van die ervaring onder gelowiges hierdie analises is. Bestaan daar nie 'n gevaar dat hierdie analises die weerspieëling is van eie individuele ervaringe en denkbeelde van 'n middelklas universiteitsprofessor nie ${ }^{5)}$ Vir ernstige wetenskaplike analises van die praktyk van gelowiges moet die Praktiese Teologie respektabele en betroubare toegangsweë soek. Daar moet opnames gemaak kan word van die ervaring van 'n verteenwoordigende deursnit waarin geslag, ouderdom, beroep en opvoedkundige peil as veranderlikes gemeet kan word. Hierdie toegang bied die empirieswetenskaplike instrumentarium. As daar nou by sommige lesers rooi- 
ligte oor die positivisme begin flits, moet $u$ saam met my eers na die moderne wetenskapsteoretiese besinning gaan kyk.

\section{2. 'n Eie wetenskaplike metode}

In ons eeu het die wetenskappe opnuut begin vra na die wesenlike. "ledere wetenschap zoekt haar grondslagen die enerzijds bepaald worden door de werkelijkheid waarop de betreffende wetenschap is gericht, anderzijds door de specifieke wijze, waarop iedere wetenschap haar eigen gebied benadert."6) Husserl noem hierdie soeke na die wesenlike, na die ware wese en die aard van die mens en van die wêreld, 'n soeke wat uit die krisis van die wetenskappe opkom. ") Te lank het die wetenskap net op blote feite gekonsentreer en gevaar geloop om ' $n$ lakei van die tegniek te word. Daar het 'n lewendige wetenskapsteoretiese diskussie in Europa ontstaan met die belangrikste skole die kritiese rasionalisme (Karl Popper en ook Hans Albert), 'n tradisie uit die Engelse wêreld, die kritiese teorie (Jürgen Habermas), fenomenologie (Husserl) en die hermeneutiese skool (Martin Heidegger en H.-G. Gadamer) uit die Duitse tradisie.

Dit is verstandig om ' $n$ mens nie onherroeplik aan één skool te verbind nie, maar om krities-evaluerend met almal om te gaan en insigte uit elke skool te neem vir die konstruering van ' $n$ metodologiese model. ${ }^{8}$ '

"The important thing is to appreciate the wealth of more traditions than one, to respect the unique contributions of each and to be on the lookout for possible points of convergence which might help one to do one's own particular job better." ${ }^{\prime 9}$ ) Die aard van die objek en die ondersoekprojek speel ' $n$ rol in die keuse van 'n spesifieke wetenskaplike metode.

Uit hierdie wetenskapsteoretiese diskussie het egter 'n paar fundamentele insigte uit die verf gekom. Daar is ingesien dat teorie onmisbaar is in wetenskapsbeoefening. Alle ondersoeke begin met 'n teorie. Hierin speel ook die lewens- en werklikheidsbeskouing van die ondersoeker, waardes en norme, die tradisie waarin jy staan en die perspei waar jy die werklikheid waarneem, 'n rol. Met hierdie teorie word die werklikheid krities en evaluerend ondersoek. Daar bestaan dus geen waardevrye en normlose empiriese ondersoeke nie. ${ }^{10)}$ Wat meer is, die ingesamelde empiriese data word met die teoretiese raamwerk geïnterpreteer. Dit beteken nie dat daar geen kritiese interaksie tussen teorie en praxis is nie. Inteendeel - en dit is nog 'n belangrike insig - die praktyk staan oop vir kritiek deur die teorie en die teorie is oop vir kritiek uit die praktyk. In hierdie immer voortgaande proses kan teorieë verstel en verbeter word. So vermeerder ons wetenskaplike kennis en so bou en 
vorm ons teorieë wat die praxis beter kan dien en rig. Die Praktiese Teologie wil deur sy empiriese oriëntasie teorie en praxis nouer op mekaar betrek. ${ }^{111}$

Teorieë moet bestaan uit duidelik afgebakende en geformuleerde konsepte en proposisies wat logies en sistematies as betroubare uitsprake aaneen sluit om 'n afgeronde geheel te vorm. Hierin speel strenge logiese argumentasie 'n belangrike rol. Eers dan (as die teorie uitgespel is) kan konsepte in die teorie geoperasionaliseer word in 'n meetinstrument waarmee die empiriese ondersoek gedoen word om die hipoteses te toets.

'n Verdere insig is dat kwalitatiewe en kwantitatiewe navorsing komplementerend en nie in opposisie teenoor mekaar staan nie. Konsensus bestaan oor die algemeen oor sekere wetenskaplike prosedures en tegnieke waarmee ondersoeke uitgevoer word.

Die Praktiese Teologie wat ernstig navraag oor sy wetenskaplikheid moes doen en wat weë soek om die praktyk wetenskaplik te ondersoek, het uiteraard veel by hierdie diskussie gebaat. Gelei deur sy unieke interesse - want interesse is ' $n$ aanvaarde oriënteringspunt vir wetenskaplike ondersoek - kan die Praktiese Teologie sy eie studieveld met sy eie metodes ondersoek met die oog op die kommunikasie en opbou van die christelike geloof.

Hierdie eie metode is veral die empiriese metode. Die teologie werk met ou vertroude metodes. Dit is die hermeneutiese metode, die historiese metode en die metodes van die taal- en literatuurwetenskap. By hierdie rytjie wil ons ook die empiriese metode voeg. As die teologie hierdie metode wil verwerp omdat dit uit die sosiale wetenskappe kom ('n ander wetenskap as die teologie dus), is die teologie oneerlik, omdat die hermeneutiese metode uit die filosofie geneem is, die historiese metode uit die geskiedeniswetenskap en die eksegetiese metodes uit die taal- en literatuurwetenskap.

Hierteen kan die beswaar geopper word dat die empiriese metode nie "geeignet", geskik is vir die teologie nie, omdat God uiteindelik aan die empirie ontsnap. Analoog hieraan sou 'n mens dit ook van die historiese en linguistiese metodes kan sê. Die punt is egter dat die Praktiese Teologie die handelinge van gelowiges in kerk, gemeente en andersins bestudeer. Dit is die sigbare handelinge in die kommunikasieproses, in die koms van God deur Sy Woord met mense as intermediêr; dit is die spore van Gods handelinge (vestigia Del) in die gemeente. Hierdie handelinge van gelowiges in diens van die Woord is sigbaar, meetbaar en oop tot verstelling met die oog op optimale kommunikasie en opbou van die geloof. Voorts is die empiriese metode wel karakteristiek van die Praktiese Teologie, maar ons vak maak ook ruimskoots gebruik van die 
ander metodes in die teologie. Trouens in elke ondersoek sal ten minste die hermeneutiese metode funksioneer. Buitendien is die ou teenstelling tussen natuurwetenskaplike en geesteswetenskaplike metodes agterhaal. Vandag word ingesien dat elke territorium van die wetenskap van alle metodes gebruik maak. Binne beide soorte wetenskappe word sowel ideografiese metodes (gerig op die verstaan) as nomotetiese metodes (gerig op die verklaring) gebruik. Dit gaan ten diepste om twee soorte metodologie wat mekaar komplementeer binne welke wetenskap ookal. 12)

Verder is die praktiese teoloog natuurlik volbloed teoloog en stel hy hom op hoogte van alle ontwikkelinge in die teologie. Daarom moet hy die metodes van die sistematiese, historiese en eksegetiese vakke beheers.

Met die empiriese metode het die Praktiese Teologie 'n eie wetenskaplike metode gevind om sy eiesoortige objek adekwaat na te vors. Min teoloë het egter in die vormingsjare geleer om empiriese instrumente te hanteer. Die vraag is nou op welke wyse ons die nodige empiriese inligting kan bekom.

\section{Fases in die soeke na prakties-teologiese kennis}

Vanaf 1774 tot ná die Tweede Wêreldoorlog het die Praktiese Teologie 'n fase gehad wat oor die algemeen as pragmaties beskryf kan word. ${ }^{13}$ ) Die kennis was geen wetenskaplike kennis nie, maar pastorale raadgewinge en resepte wat aan die studente deurgegee is.

By die behoefte aan wetenskaplike kennis wat in die tweede helfte van ons eeu ontstaan, gaan die vak 'n tweede fase binne wat ons die multidissiplinêre fase kan noem. Hierdie model verloop in twee fases. In die eerste fase doen die sosiaal-wetenskaplike sy ondersoek met sy eie teorieë en op sy eie wyse. Hierin staan die sosiale wetenskappe sentraal. Pas hierna, in die tweede fase, word teologies deur die Praktiese Teologie op die resultate gereflekteer. Voorbeelde van multidissiplinêre werk is die vyfdelige Handbuch der Pastoraltheologie en by ons te lande Kerkspieël, met M. Smuts jr. as redakteur.

Hierdie model funksioneer ook by die leen van sosiaalwetenskaplike insigte by die sielkunde, sosiologie en kommunikasiekunde wat dan in die prakties-teologiese besinning verwerk word. Daarmee is daar natuurlik op sigself nie fout nie. Insigte word in haas alle vakke oor en weer by mekaar oorgeneem en dit moet ons steeds doen. In die Praktiese Teologie word egter dikwels eklekties gewerk sonder navraag hoe aan die insigte gekom is. In hierdie werkswyse word die sosiale wetenskappe gewoonlik 'hulpwetenskappe' genoem. Hierdie opmer- 
kinge word nie as beskuldiging bedoel nie. Ons moes almal maar so werk. Dit is egter nie meer bevredigend nie.

Daar is naamlik ernstige probleme met multidissiplinêre samewerking. W.D. Jonker het tereg die kommer uitgespreek dat die teorieë van die sosiale wetenskappe die Praktiese Teologie sal binnedring en dat hierdie vak so sy teologiese karakter sal verloor. ${ }^{14)}$ As die Praktiese Teologie in die tweede fase op die empiriese gegewens van die sosiale wetenskappe reflekteer, word dit afhanklik gemaak van die sosiale wetenskappe. Dieselfde afhanklikheid geld by die inligting wat van hierdie vakke geleen word. Ons word veral afhanklik gemaak van hul teorieë (onderliggend aan hul ondersoeke) wat aan die teologie vreemd is en wat geen lig by die Skrif opgesteek het nie.

Verder is dit so dat die inligting wat die sosiale wetenskappe oor die godsdiens versamel het, groot gapings vertoon. Heel belangrike temas vir kerk en godsdiens word nie aangesny nie. Dit is geen wonder nie, omdat hul interesse elders lê en nie in die eerste plek by die geloofshandelinge van gemeentelede nie, wat die terrein van die Praktiese Teologie is. Bowendien is die studies van die sosiale wetenskappe meestal nie gerig op die praktyk van die kerk nie, maar eerder op die godsdiens in die algemeen. ${ }^{15}$ )

Wat die kwaliteit van sosiaal-wetenskaplike studies op die terrein van die Praktiese Teologie betref, word dit dikwels gekenmerk deur 'n totale afwesigheid van 'n teorie omtrent godsdiens en kerk. Soos reeds gesê, werk hulle met hul eie (aan die teologie vreemde) teorieë. Analises deur Nederlandse praktiese teoloë van die bekende sosiaalwetenskaplike ondersoek God in Nederland / en // het getoon dat 'n teorie oor godsdiens en kerk glad nie die ondersoek ten grondslag lê nie. ${ }^{16)}$ Dit roep ' $n$ ernstige probleem op, naamlik dat ons in ons afhanklikheid van hulle nie kan vasstel of ons teologiese teorieë waterhou in die praktyk van die kerk nie. Elke reggeaarde praktiese teoloog brand om teologies gestempelde empiriese inligting te verkry oor die funksionering van die bedieninge van die kerk en die geloofshandelinge van gemeentelede. Want eers dan kan ons praktiesteologiese teorieë oor hierdie sake krities evalueer en verstel met dieper insigte uit die Skrif en die praktyk.

'n Vérdere probleem is die begrippe en konsepte van die sosiale wetenskappe (hul wetenskaplike taalspel) ${ }^{17}$ ) wat in die eerste fase van ondersoek en andersins gebruik word en wat vreemd aan die teologie is. Die teologiese taalspel het sy eie begrippe en konsepte. Die oorskakeling van die een taalspel na die ander gaan met geknars gepaard. Die vraag rys onwillekeurig of daar soms dalk géén oorskakeling plaasvind nie.

Die onbehae oor die multidissiplinêre opset het die Praktiese 
Teologie in die fase van interdissiplinêre samewerking gestoot. Die groot behoefte van die Praktiese Teologie is steeds om relevante empiries-wetenskaplike kennis te verkry, sodat ons oor ons teorieë en praktyk wetenskaplik kan reflekteer, ten einde tot grondiger teoretisering en gevolglik ' $n$ beter praktyk te kan kom. Hierdie behoefte het in ' $n$ drang ontwikkel om insig te verkry in die metodes, prosedures en tegnieke waarmee empiriese gegewens ingesamel word. Die aangewese weg was 'n interdissiplinêre gesprek tussen ons vak en die sosiale wetenskappe. Die verskil tussen die multidissiplinêre en die interdissiplinêre benadering is dat die verskillende dissiplines nie los van mekaar en ná mekaar aan die bod kom nie, maar nou in interaksie met mekaar. ${ }^{18)}$ Hierdie gesprek vereis egter gelyke gespreksgenote.

In die situasie van die interdissiplinêre samewerking word egter hoë eise aan die praktiese teoloog gestel. Die gesprek moet funksioneer op die vlak van permanente kritiese diskussie en wedersydse toetsing van metode en bevindinge. Hierdeur is baie energie en tyd opgeneem. Hierdie hoë eis word goed deur Van der Ven saamgevat: "De resultaten van beide wetenschappelijke benaderingen worden niet klakkeloos door de ander overgenomen, maar beoordeeld op hun geldigheid en betrouwbaarheid, zoals evenmin de wijzen waarop deze resultaten zijn verkregen, aan de wederzijdse kritiek wordt onttrokken. De vragen waarop de resultaten geacht worden een antwoord te verschaffen, dienen evenzeer voor kritische diskussie in aanmerking te komen. Ook de wetenschapstheoretische vooronderstellingen van beider onderzoekingen, welke ten grondslag liggen aan de vraagstellingen, methoden en technieken, en de soort van resultaten die daarmee verkregen zijn, dienen onder het mes van de rede te worden geplaatst. Een heel program! En ook: een heel pakket eisen! Wie is de theoloog die nu reeds over voldoende bekwaamheden meent te beschikken om het onderzoekswerk van sociale wetenschappers ter zake kundig te kunnen evalueren?"19)

Die gesprek moet dus op die volgende gerig word: op die wetenskapsteoretiese vooronderstellinge van die sosiale wetenskappe en die Praktiese Teologie; op kennisteoretiese en normatiewe aspekte wat hierin na vore kom; op die interesses van beide dissiplines; op die metodes, prosedures en tegnieke wat gebruik word; op die resultate wat verkry word. Sommige van ons het die tyd, moeite en geld wat hieraan verbonde is, aangedurf en in gesprek getree - hier en oorsee. Algaande, soos wat ons kennis van die empiriese metodes uitgebrei het, het die besef gegroei dat ons selfstandig moet word op hierdie terrein en op 'n mondige wyse sélf op ons eie wyse hierdie metodes moet hanteer.

Dit beteken nie dat die interdissiplinêre gesprek beëindig is nie - 
inteendeel. Dit beteken egter dat ons hierdie gesprek op gelykwaardige wyse kan hervat of voortsit wanneer ons in ons eie selfstandige werk goed gevestig is.

\section{4. 'n Selfstandige weg in die beoefening van ons vak}

Die weg wat ons nou inslaan, is om self ons eie empiriese ondersoeke te doen. Ons doen dit op 'n prakties-teologiese wyse en nie op 'n sosiologiese of sielkundige wyse nie. Dit beteken dat ons met praktiesteologiese teorieë werk, soos byvoorbeeld die teorie oor die preekvoorbereiding, of oor die verstaan van die teks vir die prediking, of oor die opbou van die gemeente, of oor die kategese, ens. Vanuit hierdie teorieë doen ons sélf die empiriese ondersoeke. Die hele navorsingsmetode is dus teologies gestempel - Praktiese Teologie kan ook die teologiese teorie vir welke christelik-kerklike praktyk ookal genoem word. ${ }^{20}$ ) Ons werk met teologiese teorieë. Die empiries-wetenskaplike metodologie en instrumentarium word net as instrument in die hand geneem om ons gegewens te verkry. Weliswaar word hierdie instrumente geslyp en geskaaf om in ons wetenskaplike territorium adekwaat te funksioneer. Geen wetenskap het patentreg op metodes nie - dit is daar tot die beskikking van alle wetenskappe. Dit beteken dat die metodes van die teologie uitgebrei word met 'n nuwe aankomeling, die empiriese metode. Deur die vak op hierdie wyse te beoefen, word die teologiese identiteit van die Praktiese Teologie behou. Die Skrif is openbaringsbron en die praktyk van die gemeente ook ' $n$ kennisbron vir die verfyning van die praktyk. ${ }^{21}$ Albei funksioneer in die teorievorming van die Praktiese Teologie.

'n Prakties-teologiese ondersoek verloop dan met die volgende stappe: Daar moet eers ' $n$ doel van die ondersoek bepaal word. Die oorkoepelende doel is natuurlik om die geloofskommunikasie en die opbou van die geloof deur die handelinge van die gelowiges (gemeentelike praktyk) met wetenskaplike kennis te dien sodat dit optimaal funksioneer tot verlossing, genesing en getuienis tot eer van God. Vir elke spesifieke ondersoek sal daar egter ' $n$ doel geformuleer word wat soos 'n rat in 'n masjien die groter doel sal dien. Ten nouste saam met die doel hang die vraag of die ondersoek deskriptief (beskrywend), eksploratief (verkennend) of hipotese-toetsend (verklarend) sal wees. Die omvang van die reeds bestaande sekere kennis is bepalend of die ondersoek deskriptief, eksploratief of hipotese-toetsend sal wees. Hoe minder wetenskaplikgetoetsde kennis ons oor die onderwerp het, hoe liewer sou ons vir 'n deskriptiewe doel kies. Hoe groter ons korpus van kennis is, hoe makliker kan ons eksploratief of hipotese-toetsend werk. ${ }^{22)}$ 
Vervolgens moet die probleem geformuleer word. In die Praktiese Teologie, waarin teorie en praxis in 'n besondere verhouding staan, sal probleme hoofsaaklik uit die praktyk opkom. ${ }^{23)}$ Nie alle probleme is werd om wetenskaplik ondersoek te word nie. Daarom moet hier goed nagedink word en deur 'n proses van probleem-uitsuiwering tot ' $n$ besluit gekom word. As 'n probleem ondersoekbaar is, moet dit duidelik omskryf en in die verslag gestel word. Uit die probleemstelling volg die hipotese of navorsingsvermoede wat op grond van ons beskikbare kennis geformuleer word as voorlopige aanname of tentatiewe oplossing van die probleem. ${ }^{24}$

Die derde stap is om die teorie wat ten grondslag van die ondersoek lê, uit te spel. Dit is ' $n$ teologiese teorie wat die bepaalde handeling in die praktyk bepaal. Die probleem word dus in die teorie gekonseptualiseer. ' $n$ Duidelike, gesistematiseerde en logiese beskrywing met duidelike konsepte moet dan die teorie uitmaak soos byvoorbeeld die teorie van die prediking of die teorie vir die praktyk van die kategeet. Hierdie teorie moet deeglik aan mekaar getimmer wees.

Om hierdie teorie in sy funksionering in die praktyk te toets, ${ }^{25}$ ) moet die begrippe en konsepte in die teorie nou geoperasionaliseer word in empiriese begrippe. Dit is die omskrywing van teoretiesteologiese begrippe in empiries-teologiese begrippe. Die verskillende konsepte moet aan die hand van indikatore en items in die vorm van uitsprake geoperasionaliseer word. ${ }^{26)}$ Hierna kan die empiries-teologiese ondersoekinstrument vervaardig word. Dit kan 'n vraelys wees wat byvoorbeeld op ' $n$ vyfpuntskaal meet, ' $n$ halfgestruktureerde ontwerp vir onderhoudvoering, of ' $n$ skedule met ' $n$ kategorieësisteem vir inhoudsanalises.

Met die betrokke meetinstrument word dan die veld van die praktyk ingegaan. Ons kan nie ál die katkisasieklasse of ál die preke in die kerk ondersoek nie. Daarom word ' $n$ verteenwoordigende steekproef gemaak uit die totale universum. Die aktiwiteit van die meting vind nou plaas. Meting is die beskrywing van kenmerke, ens., van die handelinge in die praktyk deur maat en getal.

Die volgende stap is die analise en interpretasie van die ingesamelde data. ${ }^{27}$ ) In die vorige stappe word die teoretiese stelsel van teologiese uitsprake deur die operasionalisasie en instrumentasie heen in 'n empiriese stelsel omgesit. Nou word die empiriese stelsel in ' $n$ getallestelsel omgesit. Deur met getalle te werk in plaas van met woordelikse omskrywinge, kan 'n mens samehange, ontwikkelinge en oorsaaklikhede vasstel. ${ }^{28)}$ Die gegewens word dus op 'n rekenaar ingevoer en met behulp van statistiese tegnieke geanaliseer. Met statistiese metodes kan die inligting wat uit die ondersoek bekom word, meer akkuraat beskryf 
word as andersins. Aan die hand van die prakties-teologiese teoretiese raamwerk word die geordende gegewens nou geïnterpreteer en gevolgtrekkings gemaak wat as bevindinge geformuleer word.

Die laaste stap vereis teologiese kreatiwiteit. Die bevindinge van die empiriese ondersoek in die praktyk word reflekterend in interaksie gebring met die bestaande teologiese teorie wat geoperasionaliseer is. Daar is dus nou 'n kritiese interaksie tussen teorie en praktyk waarin ook die teorie oopstaan vir bystelling en verstelling. In die proses kan die teologiese konsepte geslyp word, kan nuwe konsepte ingevoer of gegenereer word. Die bedoeling is om met ' $n$ prakties-teologiese teorie te kom wat aan die Skrif getrou is, veral wat die oorsprong, opdrag en doel van ' $n$ spesifieke christelik-kommunikatiewe handeling is. Hierdie teorie moet egter ook die praxis opskerp, verbeter, ondersteun en rig. So word ons teorieë teologies verdiep en meer praktyk-relevant gemaak.

'n Mens kan ook empiriese ondersoeke wat teorie-uitbouend ${ }^{28)}$ is, onderneem vanuit die praktyk. ${ }^{30}$ ) Diegene wat in die praktyk staan, het almal ' $n$ implisiete teorie wat hul praxis beïnvloed. Vanweë die druk van die praktyk het hulle geen tyd om hul teorieë uit te spel en daaroor te reflekteer nie. Soms is hulle nie eens bewus daarvan dat daar ' $n$ teorie as onderbou van hul praktyk funksioneer nie, of hulle weet nie hoe om so 'n teorie te formuleer nie. Uit die empiriese data kan so 'n teorie geïdentifiseer en omskryf word. Deur dit te evalueer aan Skrif en praxis, kan dit verstel word vir 'n sinvoller praktyk asook 'n bydrae maak tot praktiesteologiese teorievorming.

Dit is aangenaam om te vermeld dat bostaande nie net meer teoretiese refleksie is oor die metode van ons vak nie. Uitstekende studies, wat hierdie metode beoefen, het reeds in ons land die lig gesien. Miskien kan ons dalk al ' $n$ mondigwording vier met onder andere die volgende studies: J.C. Müller, Die homilie as wyse van eietydse prediking. (D.D.-proefskrif, U.P. 1983); L.K. Louw, Dienswerk: 'n Eietydse bedieningsmodel vir die opbou van die gemeente. (D.Th.-proefskrif, Unisa 1984); N.J. Hanekom, Die beeld van 'n kerk: 'n Teologiese evaluering van die beeld wat die Ned. Geref. Kerk via sy amptelike blad 'Die Kerkbode' projekteer, (D.Th.-proefskrif, Unisa 1983); J.W. Saunderson, 'n Praktykteorie vir die kategeet in die Ned. Geref. Kerk, (D.Th.-proefskrif, Unisa 1985); H.J.C. Pieterse, Verwoording en prediking, (N.G. Kerkboekhandel, 1985). In Nederland het daar pas die volgende verskyn in die reeks Theologie en Empirie, uitgegee deur J.H. Kok te Kampen: H.J.M. Vossen, Vrijwilligerseducatie en pastoraat aan rouwenden. 


\section{Slot}

Vir ons wat nie in ons universitêre opleiding die empiriese metodes leer hanteer het nie, is hierdie metode 'n moeilike opgaaf. Ons kollegas in die eksegese moes egter ook 'n dekade of wat gelede die moeilike struktuuranalitiese metode onder die knie kry. Dit is nou ons beurt om die hand aan die ploeg te slaan. Dit is my oortuiging dat die toevoeging van die empiriese metode by die hermeneutiese, historiese en taal- en literatuurwetenskaplike metodes die teologie nie sal verarm nie, maar eerder sal verryk.

\section{NOTAS}

1. Vgl. Don S. Browning (ed.), Practical Theology, San Francisco 1983, 15.

2. G. Ebeling, Wort und Glaube, Dritter Band. Tübingen 1975; E. Schillebeeckx, Geloofsverstaan: interpretatie en kritiek, Bloemendaal 1972; J. Macquarrie, De beginselen van de christelijke theologie, Roermond 1968; H.M. Kuitert, Wat heet geloven? Baarn 1977, veral 129-159.

3. Vgl. G. Ebeling. a.w., 3 e.v., 166; vgl. ook H. Stirnimann. "Erwägungen zur Fundamentaltheologie", Freiburger Zeitschrift für Philosophie und Theologie, 24 (1977), $334-350$.

4. Vgl. J.A. van der Ven, "Op weg naar een empirische theologie", in: Meedenken met Edward Schillebeeckx. Baarn 1983. 93.

5. J.A. van der Ven, a.w., 108-109.

6. B. Delfgaauw, De wijsbegeerte van de 20 eeuw, Baarn 1976, 31.

7. Vgl. E. Husserl, Die Krisis der Europäischen Wissenschaften und die Tranzendentale Phänomenologie, The Hague 1962.

8. Vgl. vir hierdie benadering J. Mouton (red.), Metodologie van die geestesweten skappe: basiese begrippe, Pretoria 1985.

9. J.S. Krüger, Studying Religion, Pretoria 1982, 23.

10. Vgl. J.A. van der Ven (red.), Pastoraal tussen ideaal en werkelijkheid, Kampen 1985, 9-32; J.A. van der Ven, "Op weg naar een empirische theologie", 95.

11. Vgl. F. Haarsma, Spiritualiteit, Baarn 1984, 15.

12. Vgl. J.A. van der Ven, "Op weg naar een empirische theologie", 94.

13. Vgl. W.D. Jonker, Theologie en praktijk, Kampen 1968, 7-8; J.A. van der Ven, "Wat is pastoraaltheologie?" in: Toekomst voor de kerk? Studies voor Frans Haarsma, Kampen 1985, 14.

14. W.D. Jonker, In diens van die Woord, Pretoria 1981, 38-42; vgl. ook N. Mette, Theorie der Praxis, Düsseldorf 1978, 136.

15. Vgl. J.A. van der Ven, "Op weg naar een empirische theologie", 98.

16. lbid.

17. Vgl. J. Mouton (red.), a.w. 3-7.

18. J.A. van der Ven, "Wat is pastoraal-theologie?", 35.

19. "Op weg naar een empirische theologie", 101.

20. Vgl. J. Firet, "De plaats van de praktische theologie binnen de theologische faculteit", in: Praktische Theologie. Een bundel opstellen over de plaats en praktijk van de christelijke gemeente, 's-Gravenhage 1980, 13; N. Mette, a.w., 327, 342; R. Zerfass, Praktische Theologie heute, München 1974; H.J.C. Pieterse, "'n Evaluer- 
ing van ondersoekmetodes vir die prediking as kommunikasieveld", Theologia Evangelica XVI1-2 (Junie 1984), 7.

21. Vgl. H.J.C. Pieterse, Verwoording en prediking, Pretoria 1985, hoofstuk 1 paragraaf 1 en 2.1.

22. Vgl. P.G. Swanborn, Methoden van sociaal-wetenschappelijk onderzoek, Amsterdam 1984, 133 e.v.; A.D. de Groot, Methodologie. Gronds/agen van onderzoek en denken in de gedragswetenschappen, Den Haag 1968.

23. Vgl. G.J. Smit, Navorsingsmetodes in die geesteswetenskappe, Pretoria 1983, 6.

24. G.J. Smit, a.w., 18.

25. Vgl. G.J. Smit, a.W., 6-7.

26. Vgl. J.A. van der Ven, Pastoraal tussen ideaal en werkelijkheid, 208-209.

27. Vgl. J. Mouton (red.), a.w., 99 e.v.

28. J.A. van der Ven, Pastoraal tussen ideaal en werkelijkheid, 213.

29. Vgl. G.J. Smit, a.W., 6.

30. Vgl. J.A. Wolfaardt, "Practical Theology. Approaches to the Subject called Practical Theology," Journal of Theology for Southern Africa No. 51 (June 1985), 60. 